\title{
Evolutionary adaptation to host plants in a laboratory population of the phytophagous mite Tetranychus urticae Koch
}

\author{
James D. Fry* \\ Department of Biology, University of Michigan, Ann Arbor, MI 48109-1048, USA
}

\begin{abstract}
Summary. For evolutionary expansion of host range to occur in an herbivore population, genetic variation in ability to survive on and/or accept new hosts must be present. To determine whether a population of the phytophagous mite Tetranychus urticae contained such variation, I established lines from the population on two hosts on which mites initially showed both high juvenile mortality and low acceptance, tomato and broccoli. In less than ten generations, mites from the line kept on each host showed both lower mortality and greater acceptance on it than mites from a control line kept on lima bean, a favorable host for $T$. urticae. Host acceptance was measured by the proportion of mites attempting to disperse from leaves of the host. The line kept on tomato but not the one kept on broccoli also increased in development rate on its host. These results and those of a similar previous experiment on cucumber indicate that $T$. urticae populations can adapt to a diversity of initially unfavorable hosts. $T$. urticae populations therefore should be able to respond to temporal and spatial variation in host availability by adapting to the most abundant hosts.
\end{abstract}

Key words: Host plant adaptation - Spider mites - Acari - Tetranychidae - Genetic variation

For evolutionary colonization of a new host to occur in a phytophagous insect population, two conditions must be met. First, selection must favor colonization of the host. Circumstances that may favor colonization have been much discussed; they include extinction of the original hosts (Linsley and MacSwain 1958) and reduced competition, predation, or parasitism on the new host (Ehrlich and Raven 1964; Bush 1974; Jaenike 1985). A second requirement that has received less attention is the presence of genetic variation for ability to recognize, accept, and survive on the new host. If such variation is lacking in an herbivore population, changes in host range that would be selectively advantageous will be prevented from occurring. In contrast, if an herbivore population harbors effectively unlimited genetic variation for characters affecting host use, selection is likely to be the primary determinant of evolutionary changes in host range (cf. Mitter and Brooks 1983; Mitter and Futuyma 1983).

\footnotetext{
* Present address and address for offprint requests: Department of Zoology, Duke University, Durham, NC 27706, USA
}

Do herbivore populations typically harbor sufficient genetic variation to be able to adapt to new hosts, or hosts that they may occasionally use but on which they perform poorly ("marginal" hosts)? At present, most information on this question comes from examples of pest species that have counteradapted to "resistant" crop varieties (reviewed in Panda 1979; Gould 1983; Futuyma and Peterson 1985). In addition, a few cases are known in which populations of an herbivore species have adapted within historical times to hosts that cause high mortality to other populations (e.g., Hsiao 1978, 1982; Hare and Kennedy 1986). The use of examples like these to evaluate the evolutionary potential of herbivore populations suffers from a bias, however, because cases in which such rapid evolution has not occurred are not taken into account (cf. Mitter and Futuyma 1983). Only a few studies have examined the ability of herbivore populations to adapt to new or marginal hosts in cases where no previous information indicated this ability was great (Shapiro 1970; Gould 1979; Heinrichs and Rapusas 1984).

Gould (1979) reported that a laboratory population of the twospotted spider mite (Tetranychus urticae Koch) rapidly adapted to a cucumber variety that was initially toxic to the mites, through both higher survival and fecundity. Gould's result suggests that populations of this polyphagous species may harbor considerable potential for adapting to marginal hosts, but no generalizations can be drawn from one experiment involving only one base population and one host. Here, I extend Gould's work by examining whether similar rapid adaptation could occur in a different base population to two other marginal hosts for $T$. urticae, a tomato variety and a broccoli variety. Because the hosts used in this study and Gould's represent a broad sample both taxonomically and chemically, the results allow tentative generalization about the genetic potential for host range expansion in $T$. urticae.

Biology of study organism. The twospotted spider mite Tetranychus urticae Koch is a broadly polyphagous member of the phytophagous family Tetranychidae. The mites feed by piercing leaf mesophyll cells and withdrawing the contents (Jeppson et al. 1975). They have been recorded from hundreds of host species in many different families (Jeppson et al. 1975). In Chowan County, North Carolina (USA), where the mites used in this study were collected, all stages of T. urticae can be found on plants year round, with feeding and development taking place on warm days throughout the winter (Brandenburg and Kennedy 1981). Mites 
in this region use wild hosts in several different families from fall to spring; corn (Zea mays L.) is the principal host from May through July, and peanut (Arachis hypogaea L.) is the principal host in August and September (Brandenburg and Kennedy 1981, 1982; Margolies and Kennedy 1985). Mites disperse between hosts on wind currents and by crawling (Brandenburg and Kennedy 1982). T. urticae males are haploid and develop from unfertilized eggs; females are produced by sexual reproduction only.

\section{Materials and methods}

Establishment and care of lines. On July 3, 1984, about 1000 T. urticae Koch (det. by E.W. Baker, 1985) were collected from several heavily infested corn plants along the border of a 20 ha field; mites had recently colonized the corn from weedy hosts at the field's edge. The mites were taken to the laboratory and transferred to potted lima bean plants (Phaseolus lunatus L., 'Henderson Bush') for rearing; the lima bean plants used were favorable for T. urticae, allowing high juvenile survival ( $>95 \%$ ) and high fecundity. The population thus established on bean (the "bean line") served as a base population. From this base population, I established three additional populations, the "tomato", "broccoli", and "minimum selection" lines. The tomato line was established eight weeks after initial collection of the mites and maintained on potted tomato plants ( $\mathrm{Lyco}$ persicon esculentum Mill., 'Rutgers 39VF'). The broccoli line was established 14 months later and maintained on potted broccoli plants (Brassica oleracea L., 'Green Comet' hybrid). Both the tomato and broccoli plants used initially caused high juvenile mortality and low fecundity of mites. In addition, mites exhibited a strong tendency to attempt dispersal from leaves of both hosts (see Results).

All plants were grown under a combination of coolwhite and Gro-lux wide spectrum fluorescent lamps (G.T.E. Products, Danvers, Mass.) on a 16:8 (L:D) photoperiod at $21-27^{\circ} \mathrm{C}\left(\overline{\mathrm{X}}=24^{\circ} \mathrm{C}\right)$. (Unless otherwise indicated below, mite-rearing and tests for host plant adaptation were conducted under the same conditions). Tomato and broccoli were grown one per pot in $10 \mathrm{~cm}$ plastic pots containing a soilless potting mix (Metro-mix 200, W.R. Grace \& Co., Cambridge, Mass.). Lima bean plants were grown 25-30 per flat $(28 \times 20 \times 6 \mathrm{~cm})$ or $15-20$ per $11 \mathrm{~cm}$ pot containing coarse-grained vermiculite. Plants were watered only with nutrient solutions, except after being introduced to enclosures containing mites or when being used for tests for host plant adaptation, when they were watered with tap water. Fry (1988 a) gives the formula for the nutrient solution used for tomato; for lima bean and broccoli, I used a modified solution containing $505.6 \mathrm{mg} / \mathrm{liter} \mathrm{KNO}_{3}$, $1180.8 \mathrm{mg} /$ liter $\mathrm{Ca}\left(\mathrm{NO}_{3}\right)_{2} \cdot 4 \mathrm{H}_{2} \mathrm{O}$, and no $\mathrm{CaCl}_{2} \cdot 2 \mathrm{H}_{2} \mathrm{O}$ or $\mathrm{KCl}$.

Rearing procedures for the bean, tomato, and broccoli lines are summarized in Table 1. Although the tomato and broccoli lines usually had at least ca. 1000 mites, the populations declined below this level on four occasions in the tomato line and on three occasions in the broccoli line. To arrest further declines in these instances, I added a flat of beans to the enclosures containing the lines; population sizes immediately before the beans were added were at least 200 . In every case, the mites reproduced rapidly on the bean plants and the population quickly reached several thousand mites. Three to four weeks after the bean plants were added, all mites were transferred back to tomato or broccoli by cutting up the bean plants and draping them over fresh tomato or broccoli plants.

The bean line was intended to serve as a control for host adaptation in the tomato and broccoli lines. At the time that the tomato line was established, however, the bean line had been in the laboratory for only eight weeks (ca. three generations); therefore it may still have been adapting to bean, and such adaptation could have resulted in correlated changes in fitness on tomato that would have made it unsuitable as a control for the tomato line. To check for this possibility, I established an additional line, the minimum selection (M.S.) line, at the same time that the tomato line was established. The M.S. line was maintained on lima bean in a way designed to minimize evolutionary change, at least within practical limits. By comparing the bean and M.S. lines in measures of fitness on tomato, I could determine whether the bean line had changed in fitness on tomato since the tomato line was established. (By the time that the broccoli line was established, the bean line had been in the laboratory for 16 months [ $>20$ generations] and was presumably not changing in fitness on broc-

Table 1. Summary of rearing procedures for bean, tomato, and broccoli lines

\begin{tabular}{|c|c|c|c|}
\hline Line & Enclosure & Plant material and rotation schedule & $\begin{array}{l}\text { Usual population } \\
\text { size }^{b}\end{array}$ \\
\hline \multicolumn{4}{|l|}{ Bean } \\
\hline Second year & $\begin{array}{l}\text { Two } 33 \times 26 \times 8 \mathrm{~cm} \text { plastic boxes, } \\
\text { open at top (tanglefoot placed } \\
\text { around rim to prevent mite escape) }\end{array}$ & $\begin{array}{l}\text { Beds of detached bean leaves placed abaxial surface } \\
\text { up on water-saturated cotton; oldest ca. } 1 / 5 \text { th replaced } \\
\text { with fresh leaves every } 2 \text { days }\end{array}$ & $>5000$ \\
\hline Tomato & $2 \times 2 \times 2.4 \mathrm{~m}$ plywood cage ${ }^{\mathrm{a}}$ & $\begin{array}{l}8 \text { potted } 6-7 \text { wk old tomato plants; oldest } 2 \text { replaced } \\
\text { with fresh plants every } 3-4 \text { days }\end{array}$ & $1000-5000^{\mathrm{c}}$ \\
\hline Broccoli & $1.3 \times 0.9 \times 0.6 \mathrm{~m}$ plywood cage ${ }^{\mathrm{a}}$ & $\begin{array}{l}10 \text { potted } 7-9 \text { wk old broccoli plants; oldest } 2 \text { replaced } \\
\text { with fresh plants every } 3-4 \text { days }\end{array}$ & $1000-5000^{\mathrm{c}}$ \\
\hline
\end{tabular}

a Plywood cages had windows with fine mesh screening for ventilation

b Population size estimates are based on extrapolating from counts of mites on randomly selected leaves and include juveniles but not eggs

c The tomato and broccoli lines were each established with ca. 4000-5000 bean line mites 
coli; therefore it should have served as an adequate control for the broccoli line).

To minimize evolutionary change in the M.S. line, I took two steps. First, I artificially made the reproductive contribution of females to the next generation as equal as possible. Second, I increased generation time by rearing the mites at $14^{\circ} \mathrm{C}$; at this temperature, egg-to-adult development took approximately six weeks (compared to eleven days at $24^{\circ} \mathrm{C}$ ) but juvenile survival was as high as at $24^{\circ} \mathrm{C}$. Each generation of the M.S. line was started with 300 fertilized adult females. Each female was allowed to lay eggs for 24 hours on a bean leaf disc $(15 \mathrm{~mm}$ diameter) held abaxial surface up on water-saturated absorbent cotton. The progeny were allowed to develop 27-36 days, after which I reduced the number of surviving mites on each disc to six; about $80 \%$ of the discs had at least this many survivors. The discs were then placed on a bed of detached lima bean leaves on wet cotton; within a short time, mites crawled off the discs and began to feed on the bean leaves. After 15 more days, most females had reached the adult stage and mated, and 300 females were randomly selected to start the next generation.

Since all of the lines were maintained in the same room, some migration of mites may have taken place between them. I took several precautions to minimize migration, including surrounding each enclosure containing mites by a $10 \mathrm{~cm}$ wide strip of Tanglefoot (Tree Tanglefoot Co., Grand Rapids MI), a sticky substance that entraps mites. To check whether the precautions were effective, I placed bean plants without mites in a cage similar to that used for the broccoli line, and kept the cage in the same room as the lines. No mites were found on these plants in the four weeks that they were monitored, suggesting that migration between lines was low, if it occurred at all.

Tests for host plant adaptation. To determine whether the tomato and broccoli lines had adapted to their hosts, I compared each to the bean line in measures of fitness and host acceptance on its host. Comparisons were performed after 7, 10 and 25 weeks of selection in the tomato line and after 11 and 21 weeks in the broccoli line. The M.S. line was included in the comparisons on tomato at 25 weeks. I used a randomized-block design that allowed simultaneous comparisons of lines in juvenile mortality, development rate, and rate of attempted dispersal from leaves of a host. Each block consisted of two cohorts of mites (three if the M.S. line was included), one from each of the lines being compared, reared in separate tanglefoot enclosures on the same leaf of a potted plant. On tomato, the tanglefoot enclosures were $2.5 \times 5.0 \mathrm{~cm}$ rectangles; the two or three enclosures in a block were on different leaflets of the same leaf. On broccoli, enclosures were $2.5 \mathrm{~cm}$ diameter rings; each block consisted of two enclosures side-by-side on a leaf. After assigning the lines to the enclosures at random, I introduced eggs into each enclosure, with the method for introduction depending on the host. On tomato, eight adult females from the appropriate line were placed in each enclosure, allowed to lay eggs for two days, and then removed. On broccoli, three females were first allowed to lay eggs for one day on a bean leaf disc; the disc was then placed inside the enclosure. Upon hatching, mites crawled off the disc onto the broccoli plant. (This method was necessary because females placed inside enclosures on broccoli often quickly ran into the tanglefoot barrier, a response seldom observed on tomato). To minimize variation caused by parental diet, all females used to lay eggs had been reared on lima bean. The mean number of progeny obtained per enclosure was 21 (range $5-47$ ) on tomato and 18 (range 10-28) on broccoli; escape from the enclosures was $<6 \%$. Progeny were allowed sufficient time to develop for some to reach the adult stage; this took 11-17 days (usually 13-15 days) on tomato and 11-13 days on broccoli (within a block, all lines were given the same amount of time to develop). The range of development times required among blocks was caused by temperature fluctuation in the laboratory (range $21-27^{\circ} \mathrm{C}$ ) and apparent intrinsic differences among leaves and plants in suitability for mite development (e.g., development rate often varied among blocks initiated on the same day). After the development period, I removed the leaves and counted the progeny under a dissecting microscope, classifying them as live adults, live juveniles, dead inside the enclosure, and caught in the tanglefoot barrier (also dead).

Because the number of progeny varied among enclosures in these tests, an association between density and survival would have affected the results. To determine whether such an association was present, I calculated Spearmann rank-correlation coefficients (Conover 1980) between the number of progeny in an enclosure and the proportion surviving for each line $\times$ test period combination. Of eleven such correlations (seven on tomato and four on broccoli), none were significant, and only five were negative.

All of the tests on tomato were conducted using the third to fifth true leaves from the base of the 6-7 week old plants. These older, fully expanded leaves were chosen because they have relatively low densities of the glandular trichomes that can sometimes entrap mites (Stoner et al. 1968).

Fifty-five to seventy-three weeks after the tomato line was established, I compared it to the bean line in fecundity on tomato and in rate of dispersal from tomato leaves when no tanglefoot enclosure was present. The purpose of these comparisons was to further characterize adaptation to tomato in the line. The fecundity comparisons were conducted in an environmental chamber under a 16:8 (L:D) photoperiod from cool white fluorescent lamps, with a corresponding $25: 23^{\circ} \mathrm{C}$ temperature cycle. To obtain females for the comparisons, I placed parent females singly on bean leaf discs, allowed them to lay eggs $(\bar{X}=8)$ for one day, and then removed them. After ten days, most of the progeny were in their final molt, and one female in the final molt was transferred from each disc to a tomato leaf disc, along with two adult males from the same line. The females emerged within two days. Four days after the initial transfer and at four day intervals thereafter, surviving females were transferred to fresh discs. Eggs were counted daily until all females died.

To compare the tomato and bean lines in rate of dispersal from tomato plants when no tanglefoot enclosure was present, I used the same design as the one described above for the tests using tanglefoot enclosures, except that mites were confined to the leaflets only by rings of tanglefoot around the leaflet bases. Mites were introduced to the leaflets by first letting parent females lay eggs on bean leaf discs and then pinning the discs to the tomato leaflets. The progeny $(\bar{X}=21$, range $10-36)$ were allowed to develop for 8-10 days, after which I removed the leaflets and counted the mites. Because dead mites do not readily fall off leaves 
(personal observation), I used the proportion of progeny missing from the leaflets as an index of dispersal. The proportion of progeny that attempted to escape through the tanglefoot around the leaflet bases provided a second dispersal index.

Statistical analysis. The tests using tanglefoot enclosures produced threee-way contigency tables in which mites were classified by line, block, and fate (i.e. live, dead inside the enclosure, or caught in the tanglefoot). I used multiway G-tests (Sokal and Rohlf 1981; BMDP 1985) to determine whether mite fate depended on line, block, and/or the line $x$ block combination. To increase expected cell frequencies for this analysis, I pooled mites dead inside the enclosure with mites in tanglefoot to create a single category of dead mites. For the 7 and 10 week tests on tomato, I also pooled all pairs of blocks that had been performed on the same leaf (survival never differed significantly between such blocks). After pooling, expected frequencies were always $>1$, and a maximum of $26 \%$ were $<5$; although this is slightly greater than the recommended maximum of $20 \%$ (BMDP 1985), further pooling of blocks had virtually no effect on significance levels.

If the G-tests indicated that a pair of lines differed in proportion surviving on a host, I used Wilcoxon matchedpairs signed-ranks tests (Conover 1980) to compare them in the proportions dead inside the enclosure and caught in the tanglefoot. The latter proportion can be considered an index of behavioral rejection of a host (Aina et al. 1972; Fry 1988a). I also used Wilcoxon tests to compare lines in the proportion of surviving mites that had reached the adult stage, an index of development rate, and in the proportions missing and in the tanglefoot on the leaflet bases in the tests examining dispersal rates from tomato (in all of these cases, expected cell frequencies would have been too low for use of $\mathrm{G}$-tests). The fecundity data on tomato were not normally distributed, with over half of the mites laying no eggs; accordingly, I used the Mann-Whitney $U$ test to compare lines. This test is not sensitive to large numbers of tied observations (Conover 1980).

\section{Results \\ Experiment on tomato}

The tomato line had significantly higher juvenile survival on tomato than the bean line after only seven weeks of selection, with the difference between the lines becoming larger at 10 and again at 25 weeks (Tables 2, 3). In contrast, the bean and minimum selection lines had nearly identical survival on tomato at 25 weeks (Tables 2,3 ). Thus, the divergence between the bean and tomato lines was caused by improvement in survival of the tomato line, rather than evolutionary change in the bean line.

There were significant block and line $\times$ block effects on survival in the 10 and 25 week tests (Table 3 ). Since blocks correspond to leaves, the block effects suggest that an effect of individual leaves on survival was present. A line $\times$ block interaction means that the difference in survival between lines varied among blocks. Because mites from the different lines within each block were on different leaflets of the same leaf, the line $\times$ block interactions may have been caused by an effect of leaflets within leaves on survival.
Table 2. Fate of tomato, bean and minimum selection (M.S.) line progeny in tanglefoot enclosures on tomato leaves after 7,10 , and 25 weeks of selection in the tomato line

\begin{tabular}{lllll}
\hline & $\begin{array}{l}\text { No. } \\
\text { blocks }\end{array}$ & \multicolumn{2}{l}{ Mean proportions } \\
\cline { 3 - 4 } & & live & $\begin{array}{l}\text { dead inside in } \\
\text { enclosures }\end{array}$ & $\begin{array}{l}\text { inglefoot } \\
\text { tang }\end{array}$ \\
\hline weeks: & & & & \\
Tomato line & 18 & 0.23 & 0.18 & 0.58 \\
Bean line & & 0.15 & 0.23 & 0.62 \\
10 weeks: & & & & \\
Tomato line & 21 & 0.41 & 0.15 & 0.44 \\
Bean line & & 0.18 & 0.26 & 0.56 \\
25 weeks: & & & & \\
Tomato line & & 0.56 & 0.11 & 0.33 \\
Bean line & 17 & 0.25 & 0.19 & 0.56 \\
M.S. line & & 0.26 & 0.19 & 0.55 \\
\hline
\end{tabular}

Table 3. Analysis of proportion surviving in tanglefoot enclosures on tomato leaves. Results of multiway $G$ tests showing the effects of different factors on survival are given

\begin{tabular}{lcrr}
\hline $\begin{array}{l}\text { Association between } \\
\text { survival and }\end{array}$ & d.f. & $G$ & $P$ \\
\hline 7 weeks: & & & \\
Line & 1 & 9.09 & 0.0026 \\
Block & $10^{\mathrm{a}}$ & 14.35 & 0.1576 \\
Line $\times$ block interaction & 10 & 10.44 & 0.4031 \\
& & & \\
weeks: & 1 & 41.69 & $<0.0001$ \\
Line & $12^{\mathrm{a}}$ & 40.86 & 0.0001 \\
Block & 12 & 24.04 & 0.0201 \\
L $\times$ B interaction & & \\
25 weeks (tomato and bean lines only): & & \\
Line & 1 & 104.12 & $<0.0001$ \\
Block & 16 & 55.08 & $<0.0001$ \\
L $\times$ B interaction & 16 & 36.13 & 0.0028 \\
25 weeks (bean and minimum selection lines only): & \\
Line & 1 & 0.16 & 0.6932 \\
Block & 16 & 38.11 & 0.0015 \\
L $\times$ B interaction & 16 & 25.29 & 0.0649 \\
\hline
\end{tabular}

a Degrees of freedom reflect pooling of blocks on same leaf (see Materials and methods)

The higher survival of tomato line than bean line mites was caused by the tomato line having both a lower proportion of mites die inside the enclosures and a lower proportion migrate into the tanglefoot barriers (Table 2). Differences between the two lines in both of these categories were significant in the 10 and 25 week tests $(P<0.05$ one-tailed, Wilcoxon signed-ranks test). Much of the mortality in all three lines was caused by mites migrating into the tanglefoot (Table 2). This phenomenon was the result of a specific avoidance response to tomato, because when mites from the bean line were tested on other host species using similar methods, $<10 \%$ migrated into the tanglefoot, even when densities of progeny were 3-4 fold higher than used for the tests on tomato (Fry, unpublished data). 
Table 4. Fecundity of tomato and bean line mites on tomato leaf discs

\begin{tabular}{|c|c|c|c|c|c|c|}
\hline & \multicolumn{2}{|c|}{ Tomato line } & \multicolumn{2}{|l|}{ Bean line } & \multirow[t]{2}{*}{$U^{\mathbf{a}}$} & \multirow[t]{2}{*}{$P^{b}$} \\
\hline & $\bar{X}(\mathrm{SD})$ & $N$ & $\bar{X}(\mathrm{SD})$ & $N$ & & \\
\hline $\begin{array}{l}\text { Mites remaining } \\
\text { on discs }\end{array}$ & $1.3(4.2)$ & 36 & $0.1(0.4)$ & 36 & 535.5 & 0.025 \\
\hline $\begin{array}{l}\text { Mites leaving } \\
\text { discs }\end{array}$ & $4.0(9.2)$ & 14 & $0 \quad(0)$ & 13 & 58.5 & 0.010 \\
\hline All mites & $2.1(6.1)$ & 50 & $0.1(0.3)$ & 49 & 949.0 & 0.002 \\
\hline
\end{tabular}

a Mann-Whitney $U$ statistic

b Significance levels are one-tailed due to prediction of higher fecundity in the tomato line

The lower proportion of tomato line mites in tanglefoot suggests that they would have had a lower tendency to disperse from tomato plants when not confined by tanglefoot enclosures than bean line mites. Confirming this prediction, significantly more bean line than tomato line mites dropped off tomato leaflets when confined only by tanglefoot around the leaflet bases (mean proportions were 0.23 and 0.14 , respectively, $N=20$ blocks; $P<0.02$ one-tailed, Wilcoxon signed-ranks test). Similarly, significantly more bean line mites attempted to escape through the tanglefoot around the leaflet bases (means were 0.10 vs. $0.02, P<$ 0.001 ).

Selection also increased development rate and fecundity on tomato. The mean proportion of surviving mites that had reached the adult stage in the tests using tanglefoot enclosures was 0.42 in the tomato line compared to 0.30 in the bean line $(P=0.004$ one-tailed, Wilcoxon signedranks test, $N=36$ blocks after exclusion of ties and blocks without surviving mites in both lines). In contrast, the bean and minimum selection lines did not differ in the proportion adults in the 25 week tests (mean proportions were 0.52 and 0.42 , respectively; $P>0.2$ two-tailed, $N=14$ blocks), again confirming that the bean line served as an adequate control for evolutionary changes in the tomato line. Analysis of the fecundity data was somewhat complicated by the fact that about $25 \%$ of the mites in both lines left the leaf discs and drowned in the surrounding wet cotton. Whether mites leaving the discs and those not leaving are considered seperately or pooled, however, tomato line mites laid significantly more eggs than bean line mites (Table 4).

\section{Experiment on broccoli}

The broccoli and bean lines did not differ in juvenile survival on broccoli after 11 weeks of selection (Tables 5,6 ). By 21 weeks, however, the broccoli line had significantly higher survival than the bean line. Significant block and line $x$ block effects were apparent in both test periods. The higher survival of the broccoli line at 21 weeks was accompanied by significantly lower proportions of mites dead inside the enclosures and caught in the tanglefoot (Table 5; $P<0.05$ one-tailed in each case, Wilcoxon signed-ranks test). At this time, however, the two lines did not differ in the proportions of live mites having reached the adult stage $(P>0.3$ one-tailed, Wilcoxon test, $N=31$ blocks after exclusion of ties; means were 0.50 and 0.46 in the broccoli and bean lines, respectively).
Table 5. Fate of broccoli and bean line progeny in tanglefoot enclosures on broccoli leaves after 11 and 21 weeks of selection in the broccoli line

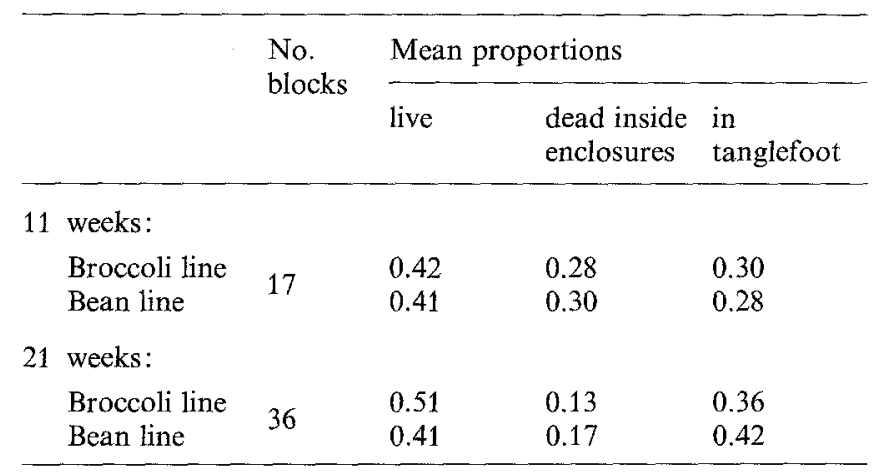

Table 6. Analysis of proportion surviving in tanglefoot enclosures on broccoli leaves. Results of multiway $G$ tests showing the effects of different factors on survival are given

\begin{tabular}{lrrr}
\hline $\begin{array}{l}\text { Association between } \\
\text { survival and }\end{array}$ & d.f. & $G$ & \multicolumn{1}{c}{$P$} \\
\hline 11 weeks: & & & \\
Line & 1 & 0.00 & 0.9803 \\
Block & 16 & 78.77 & $<0.0001$ \\
Line $\times$ block interaction & 16 & 34.41 & 0.0048 \\
21 weeks: & & & \\
Line & 1 & 13.06 & 0.0003 \\
Block & 35 & 86.01 & $<0.0001$ \\
L $\times$ B interaction & 35 & 83.50 & $<0.0001$ \\
\hline
\end{tabular}

\section{Discussion}

The results of this study and Gould's (1979) indicate that a single $T$. urticae population can contain considerable potential for adapting to hosts on which survival and reproduction is initially low. In this study, the selected lines on both tomato and broccoli showed both decreased juvenile mortality and higher host acceptance on their hosts in under ten generations. The tomato line also increased in development rate on tomato in this time, and by fifty-five weeks of selection (ca. 20 generations) had higher fecundity on tomato than the control line. Gould's (1979) selected population on cucumber similarly evolved higher survival and fecundity (but not higher development rate) on cucumber within several generations.

The success of the selection experiments on tomato, broccoli and cucumber suggests that $T$. urticae populations are able to adapt to hosts containing a diversity of adverse characteristics for mites, possibly through a diversity of mechanisms. Each of the three hosts is a member of a different plant family known to be characterized by a different set of secondary chemicals (alkaloids in Solanaceae, glucosinalates in Cruciferae, and triterpenoids in Cucurbitaceae; Rosenthal and Janzen 1979). In addition, the hosts differ in mechanical attributes that may affect mites: tomato possesses glandular trichomes that can entrap mites, broccoli possesses a thick waxy cuticle that mites may have difficulty in penetrating, while cucumber has no obvious adverse mechanical features for mites. Differences in the initial response of mites to the three hosts give further evidence that different plant characteristics caused the initial low 
success of mites in each case, with correspondingly different mechanisms of adaptation necessary in the mites. In Gould's study, mites seldom attempted to disperse from cucumber and appeared to feed on it readily (Gould 1979 and personal communication); the initial low success of mites was probably caused by ingested toxins (Gould 1978 a). Correspondingly, adaptation of the selected line to cucumber was apparently based on physiological changes leading to decreased susceptibility to the toxins (Gould et al. 1982). In contrast, the high rates of attempted dispersal from tomato and broccoli leaves observed in this study indicate that these hosts had features that inhibited mites from feeding, either by causing behavioral aversion or by physically hindering feeding. As suggested by the increased tendency of the selected lines to remain on tomato and broccoli leaves, adaptation to these hosts may have been based largely on increased willingness or ability to feed on them. In spite of the similarity of the behavioral responses to tomato and broccoli, however, development rate on tomato was initially slower than on broccoli (Fry, unpublished data) but increasd in response to selection, suggesting that tomato had some adverse feature that mites were able to adapt to that was not found in broccoli.

Given that T. urticae populations can adapt to a diversity of marginal hosts, the host range of mite populations should be able to evolve in response to changed environmental conditions. For example, an increase in the amount of tomato, broccoli or cucumber grown in an area should result in an increase in level of adaptation of $T$. urticae populations to the host (cf. Gould 1979). A decrease in the abundance of alternate hosts might have the same effect, as proportionately more mites would experience selection on tomato, broccoli or cucumber. Mite populations should also be able to respond to spatial variation in host availability by adapting to the hosts in a single field or patch over the course of a growing season. Gould (1978b) and Fry (1988a) present some evidence for such local adaptation to cucumber and tomato, respectively.

The rate of adaptation of natural T. urticae populations to a marginal host is likely to depend not only on the host's relative abundance but on how behaviorally acceptable it is to mites, and also on whether genetic variation for acceptance is present. Adaptation would be likely to proceed more rapidly to a marginal host that is accepted readily (e.g. cucumber) than to one that is often rejected (e.g. tomato or broccoli), because fewer mites would experience selection on the latter type of host (cf. Gould 1984). In addition, if genetic variation for tendency to accept a marginal host were present, selection could result in decreased acceptance of the host provided more favorable alternative hosts were available, thereby further weakening selection for higher fitness on the host (Gould 1984; Castillo-Chavez et al. 1988). The precise outcome would also depend on the sign and magnitude of the genetic covariance between tendency to accept the marginal host and fitness on it once accepted (Via 1986). For example, if this covariance were positive, selection for avoidance of the host would result in lower fitness on it, thereby further strengthening the selection for avoidance. Although this study documented genetic variation for both fitness on tomato and broccoli and tendency to accept these hosts, further work would be needed to determine the genetic covariance between fitness and acceptance on each host.

Although my results and Gould's (1979) show that $T$. urticae populations can rapidly adapt to marginal hosts, it would be premature to conclude that there are no limits to the genetic potential for host range expansion in this species. All of the hosts chosen for the selection experiments allowed some survival and reproduction initially; the results might have been very different if hosts initially giving $0 \%$ juvenile survival had been used. Adaptation to such a host could occur only if a genotype able to survive on it arose by mutation or some other genetic alteration; if several independent mutations were required to produce such a genotype, the chance of it arising might be close to zero. Furthermore, although juvenile survival of $T$. urticae on many hosts is well over 90\% (Gould 1978a; Fry 1988b and unpublished data), neither Gould's population on cucumber or the tomato line attained this level in over 30 generations of selection (Gould 1979; Fry 1988b and in preparation). Larger responses might have been obtained with more time or bigger populations, but this cannot be assumed.

The observation of widespread genetic variation for fitness on particular hosts in T. urticae also raises the question of how this variation is maintained. Why were not the base populations already at a selection limit for fitness on the hosts used for the selection experiments? Two possible explanations can be considered. First, the hosts may have been encountered so infrequently in the history of the populations that selection against alleles conferring low fitness on them may have been extremely weak. If selection is sufficiently weak, appreciable amounts of genetic variation can be maintained by mutation-selection balance (e.g., Ohta and Kimura 1975). An alternate possibility is that the hosts were encountered more frequently, but selection for adaptation to them was opposed by selection taking place on other hosts. This hypothesis requires that there be "trade-offs"in fitness on different hosts: that is, that the optimal genotype or character state on one host is not the same as on others. Although such trade-offs have not been found in several studies of other herbivores (Rausher 1984; Via 1984; Weber 1985; Hare and Kennedy 1986; Futuyma and Philippi 1987; James et al. 1988; Karowe 1988), Gould (1979) presented some evidence that a trade-off was present between fitness on cucumber and fitness on lima bean in his population. Elsewhere (Fry, in preparation), I address whether a trade-off was present between fitness on tomato and fitness on bean in the T. urticae population used in this study.

Acknowledgments. I thank D. Goldberg, F. Gould, P.R. Grant, B. Rathcke, and P. Smouse for advice and encouragement during the course of this study. G.G. Kennedy and D. Smitley kindly collected the mites, and B. Hazlett provided much-needed laboratory space. H.L. Gibbs, D. Goldberg, F. Gould, D. Karowe, W.S. Lawrence, B. Rathcke, M. Rausher, P. Smouse and two anonymous reviewers made helpful comments on earlier versions of the manuscript. The work was supported by grants from the Graduate School of the University of Michigan and Sigma Xi. The Matthaei Botanical Gardens of the University of Michigan provided materials for growing plants. This paper is based on research conducted for the author's Ph.D. dissertation.

\section{References}

Aina OJ, Rodriguez JG, Knavel DE (1972) Characterizing resistance to Tetranychus urticae in tomato. J Econ Entomol 65:641-643

BMDP (1985) BMDP statistical software manual. Univ California Press, Berkeley CA 
Brandenburg RL, Kennedy GG (1981) Overwintering of the pathogen Entomophthora floridana and its host, the twospotted spider mite. J Econ Entomol 74:428-431

Brandenburg RL, Kennedy GG (1982) Intercrop relationships and spider mite dispersal in a corn/peanut agro-ecosystem. Entomol Exp Appl 32:269-276

Bush GL (1974) The mechanism of sympatric host race formation in the true fruit flies (Tephritidae). In: White MJD (ed) Genetic mechanisms of speciation in insects. Australia and New Zealand Book Co, Sydney, pp 3-23

Castillo-Chavez C, Levin SA, Gould F (1988) Physiological and behavioral adaptation to varying environments: a mathematical model. Evolution 42:986-994

Conover WJ (1980) Practical nonparametric statistics, 2nd ed. John Wiley and Sons, New York

Ehrlich PR, Raven PH (1964) Butterflies and plants: a study in coevolution. Evolution 18:586-608

Fry JD (1988a) Variation among populations of the twospotted spider mite, Tetranychus urticae Koch (Acari: Tetranychidae), in measures of fitness and host-acceptance behavior on tomato. Environ Entomol 17:287-292

Fry JD (1988b) Genetic variation and genetic correlations in hostspecific fitness in the phytophagous mite Tetranychus urticae Koch. PhD Diss Univ Michigan, Ann Arbor MI (Available from Univ Microfilms Int, $300 \mathrm{~N}$ Zeeb Rd, Ann Arbor MI 48106 USA)

Futuyma DJ, Peterson SC (1985) Genetic variation in the use of resources by insects. Annu Rev Entomol 30:217-238

Futuyma DJ, Philippi TE (1987) Genetic variation and covariation in responses to host plants by Alsophila pometaria (Lepidoptera: Geometridae). Evolution $41: 269-279$

Gould F (1978a) Resistance of cucumber varieties to Tetranychus urticae: genetic and environmental determinants. J Econ Entomol 71:680-683

Gould F (1978b) Predicting the future resistance of crop varieties: a case study of mites and cucumbers. Environ Entomol $7: 622-626$

Gould F (1979) Rapid host range evolution in a population of the phytophagous mite Tetranychus urticae. Evolution 33:791-802

Gould F (1983) Genetics of plant-herbivore systems: interactions between applied and basic study. In: Denno RF, McClure MS (eds) Variable plants and herbivores in natural and managed systems. Academic Press, New York, pp 599-653

Gould F (1984) Role of behavior in the evolution of insect adaptation to insecticides and resistant host plants. Bull Entomol Soc Am 30:34-41

Gould F, Carroll CR, Futuyma DJ (1982) Cross-resistance to pesticides and plant defenses: a study of the twospotted spider mite. Entomol Exp Appl 31:175-180

Hare JD, Kennedy GG (1986) Genetic variation in plant-insect associations: survival of Leptinotarsa decemlineata populations on Solanum carolinense. Evolution 40:1031-1043

Heinrichs EA, Rapusas HR (1984) Feeding, development, and tungro virus transmission by the green leafhopper, Nephotettix virescens (Distant) (Homoptera: Cicadellidae) after selection on resistant rice cultivars. Environ Entomol 13:1074-1078

Hsiao TH (1978) Host plant adaptations among geographic populations of the Colorado potato beetle. Entomol Exp Appl $24: 237-247$
Hsiao TH (1982) Geographic variation and host plant adaptation of the Colorado potato beetle. In: Proc 5th Int Symp InsectPlant Relationships, Wageningen 1982. Pudoc, Wageningen, The Netherlands, pp 315-324

Jaenike J (1985) Parasite pressure and the evolution of amanitin tolerance in Drosophila. Evolution 39:1295-1301

James AC, Jakubczak J, Riley MP, Jaenike J (1988) On the causes of monophagy in Drosophila quinaria. Evolution 42:626-630

Jeppson LR, Keifer HH, Baker EW (1975) Mites injurious to economic plants. Univ California Press, Berkeley CA

Karowe DN (1988) Ecological and evolutionary determinants of larval host plant range in the sulfur butterflies, Colias philodice and Colias interior. PhD Diss Univ Michigan, Ann Arbor MI

Linsley EG, MacSwain JW (1958) The significance of floral constancy among bees of the genus Diadasia (Hymenoptera: Anthophoridae). Evolution 12:219-223

Margolies DC, Kennedy GG (1985) Movement of the twospotted spider mite, Tetranychus urticae, among hosts in a corn-peanut agroecosystem. Entomol Exp Appl 37:55-61

Mitter C, Brooks DR (1983) Phylogenetic aspects of coevolution. In: Futuyma DJ, Slatkin M (eds) Coevolution. Sinauer Associates, Sunderland MA, pp 65-98

Mitter C, Futuyma DJ (1983) An evolutionary-genetic view of host-plant utilization by insects. In: Denno RF, McClure MS (eds) Variable plants and herbivores in natural and managed systems. Academic Press, New York, pp 427-459

Ohta T, Kimura M (1975) Theoretical analysis of electrophoretically detectable polymorphisms: models of very slightly deleterious mutations. Am Nat 109;137-145

Panda N (1979) Principles of host-plant resistance to insect pests. Allanheld/Universe, New York

Rausher MD (1984) Tradeoffs in performance on different hosts: evidence from within- and between-site variation in the beetle Deloyala guttata. Evolution 38:582-595

Rosenthal GA, Janzen DH, eds (1979) Herbivores: their interaction with secondary plant metabolites. Academic Press, New York

Shapiro AM (1970) Disruptive selection and conditioning as factors in host-race formation in a phytophagous insect, Pieris protodice (Lepidoptera:Pieridae). PhD Diss Cornell Univ, Ithaca, NY

Sokal RR, Rohlf FJ (1981) Biometry, 2nd ed. WH Freeman and Co, San Francisco

Stoner AK, Frank JA, Gentile AG (1968) The relationship of glandular hairs on tomatoes to spider mite resistance. Proc Am Soc Hortic Sci 93: 532-538

Via S (1984) The quantitative genetics of polyphagy in an insect herbivore. II. Genetic correlations in larval performance within and among host plants. Evolution 38:896-905

Via S (1986) Genetic covariance between oviposition preference and larval performance in an insect herbivore. Evolution 40:778-785

Weber G (1985) Genetic variability in host plant adaptation of the green peach aphid, Myzus persicae. Entomol Exp Appl 38: 49-56

Submitted July 8, 1989 / Accepted August 21, 1989 